\title{
Pengaruh Dana Pihak ketiga Non Performing Loan dan Suku Bunga Kredit terhadap Profitabilitas pada PT. BPR Suryajaya Ubud
}

\author{
Ni Kadek Egi ${ }^{1}$, Ade Maharini Adiandari ${ }^{2}$ \\ ${ }^{1,2}$ Fakultas Ekonomi, Universitas Ngurah Rai, Bali, Indonesia \\ ${ }^{1}$ kadekegi793@gmail.com, ${ }^{2}$ maharini.adiandari@unr.ac.id \\ * Ade Maharini Adiandari
}

\section{A R T I C L E I N F O}

Article history

Received 2020-10-12

Revised 2020-10-22

Accepted 2020-10-31

Keywords

$D P K, N P L$, Interest Rates, and ROA.

\begin{abstract}
AB STRAC T
This study aims to determine the effect simultaneously or partially on profitability at PT. BPR Suryajaya Ubud for the period 2013-2016. The sample used was 48 DPK, NPL, Loan Interest Rates, and ROA data. Data were analyzed using the classic assumption test, multiple linear regression test, determination analysis, simultaneous significance test (F-test), and partial significance test (t-test). The results in this study indicate that Third Party Funds have partially negative and significant effect on ROA. Non Performing Loans partially have a negative and significant effect on ROA. Credit interest rates partially have a positive and significant effect on ROA. DPK, NPL, and Credit Interest rates simultaneously have a significant effect on ROA at PT. BPR Suryajaya Ubud in 2013-2016.
\end{abstract}

\section{A. PENDAHULUAN}

Profitabilitas perusahaan adalah suatu ukuran kemampuan perusahaan untuk menghasilkan laba, baik dengan menggunakan seluruh aktiva yang ada maupun dengan modal sendiri, sehingga dapat diketahui tingkat profitabilitas perusahaan untuk mengambil keputusan maupun untuk kepentingan bersama (Moeljadi, 2006:6).

Menurut Kasmir (2014:196), laba yang dicapai sesuai target dapat memberikan kesejahteraan bagi stakeholders, dapat meningkatkan mutu produk, serta dapat digunakan untuk melakukan investasi baru. Oleh karena itu, manajemen perusahaan dalam praktiknya dituntut harus mampu untuk memenuhi target yang telah ditetapkan. Dalam praktiknya, terdapat beberapa indikator rasio profitabilitas yang sering digunakan perusahaan. Salah satunya adalah indikator ROA.

ROA (Return On Assets) merupakan rasio yang digunakan untuk mengukur kemampuan manajemen perusahaan dalam memperoleh keuntungan (laba) secara keseluruhan. Semakin besar ROA suatu perusahaan maka semakin besar pula tingkat keuntungan yang dicapai perusahaan dan semakin baik pula posisi perusahaan tersebut dari segi penggunaan aset (Sawir 2005:18). ROA dipakai untuk mengevaluasi apakah manajemen telah mendapat imbalan yang memadai (reasobable return) dari aset yang dikuasainya. Rasio ini merupakan ukuran yang tepat jika seseorang ingin mengevaluasi seberapa baik perusahaan telah memakai dananya. Oleh karena itu, ROA sering kali dipakai oleh manajemen puncak untuk mengevaluasi unit-unit bisnis di dalam suatu perusahaan multinasional (Henry Simamora, 2005:530).

Setiap perusahaan perbankan akan menghadapi permasalahan yang berbeda-beda, mulai dari penerimaan dana maupun penyaluran dana. Salah satunya adalah di PT. BPR Suryajaya Ubud yang merupakan salah satu lembaga keuangan Bank Perkreditan Rakyat yang terletak di Gianyar. Berikut adalah data ROA, DPK, Total Kredit, Kredit Bermasalah, dan NPL pada PT. BPR Suryajaya Ubud. 
Tabel 1. Data ROA, DPK, Total Kredit, Kredit Bermasalah, dan Persentase NPL di PT. BPR Suryajaya Ubud Periode 2013 - 2016

\begin{tabular}{|c|c|c|c|c|c|}
\hline \multirow[b]{2}{*}{ Tahun } & \multicolumn{5}{|c|}{ Keterangan } \\
\hline & $\begin{array}{l}\text { ROA } \\
(\%)\end{array}$ & $\begin{array}{l}\text { DPK } \\
\text { (Rp. 000) }\end{array}$ & $\begin{array}{l}\text { Total Kredit } \\
\text { (Rp. 000) }\end{array}$ & $\begin{array}{l}\text { Kredit } \\
\text { Bermasalah } \\
\text { (Rp. 000) }\end{array}$ & $\begin{array}{l}\text { NPL } \\
(\%)\end{array}$ \\
\hline 2013 & 4.68 & $21,436,858$ & $77,005,860$ & $6,508,482$ & $8.45 \%$ \\
\hline 2014 & 4.37 & $25,898,149$ & $73,204,693$ & $7,797,612$ & $10.65 \%$ \\
\hline 2015 & 4.38 & $29,429,236$ & $74,817,519$ & $7,306,523$ & $9.77 \%$ \\
\hline 2016 & 2.49 & $31,735,858$ & $88,191,776$ & $12,297,575$ & $13.94 \%$ \\
\hline
\end{tabular}

Sumber : PT. BPR Suryajaya Ubud 2019 (data diolah)

Nilai NPL yang dimiliki pada tahun 2013-2016 rata-rata adalah 10,70\%, angka yang sangat tinggi jika dibandingkan dengan penetapan standar NPL yang tinggi menurut Bank Indonesia yaitu sebesar 5\%. Melihat angka yang tinggi tersebut menyebabkan ROA mengalami penurunan hingga 2,49\% dan sangat rendah jika dibandingkan dengan angka kesehatan Bank yaitu diatas 5\%, sehingga PT. BPR Suryajaya Ubud dalam rentang tahun 2013-2016 dikategorikan Bank yang tidak sehat.

Namun dalam penghimpunan dana, PT. BPR Suryajaya Ubud selalu mengalami peningkatan pada tahun 2013-2016, peningkatan dana tersebut mencapai Rp. 31.735 .858 (dalam ribuan). Namun hal tersebut tidak memberikan peningkatan terhadap ROA, selain itu suku bunga kredit yang rendah juga tidak mendukung pertumbuhan ROA karena besarnya kerugian yang disebabkan NPL yang tinggi.

Kualitas Bank yang tidak sehat akan mempengaruhi keadaan perkembangan Bank tersebut di masa yang akan datang, dan juga akan mempengaruhi minat nasabah dalam meminjam maupun menenmpatkna dana tersebut. Jika hal tersebut terus terjadi maka laba atau pendapatan yang dimiliki Bank akan terus tergerus untuk menutupi kerugian tersebut dan operasional Bank tidak akan berjalan dengan baik.

Non Performing Loan, Suku Bunga Kredit dalam usaha meningkatkan ROA, maka sangat layak dalam dalam penelitian ini diteliti lebih jauh lagi, sehingga judul yang diangkat adalah pengaruh Dana Pihak Ketiga, Non Performing Loan dan Suku Bunga Kredit terhadap Return On Assets.

\section{B. METODE PENELITIAN}

Desain penelitian ini termasuk dalam penelitian kuantitatif yaitu penelitian asosiatif atau relasi, yaitu penelitian untuk mengetahui keberadaan hubungan suatu vaiabel penelitian dan kaitannya dengan variabel lainnya. Penelitian ini dilaksanakan di PT. BPR Suryajaya Ubud yang beralat di Jalan Raya Kemenuh Sukawati Gianyar Bali. Sampel yang digunakan dalam penelitian ini adalah seluruh jumlah populasi yang merupakan seluruh data DPK, NPL, Suku Bunga Kredit dan ROA tahun 20132016 yaitu sebanyak 48 .

Teknik pengumpulan data yang dilakukan dengan cara wawancara, observasi, dan studi dokumentasi. Teknik analisis data dalam penelitian ini menggunakan teknik pendekatan kuantitatif yang terdiri dari uji asumsi klasik, analisis regresi linear berganda., uji determinasi, uji signifikansi simultan (f-test), dan uji signifikansi parsial (t-test).

\section{HASIL DAN PEMBAHASAN}

\section{Uji asumsi klasik}

Uji asumsi klasik digunakan untuk mnegetahui kelayakan penggunaan model regresi. Hasil uji normalitas dapat dilihat pada Tabel 2. 
Tabel 2. Hasil Uji Normalitas dengan Uji Kolmogrov-Smirnov

\begin{tabular}{|l|r|}
\hline & $\begin{array}{l}\text { Unstandardized } \\
\text { Residual }\end{array}$ \\
\hline $\mathrm{N}$ & 48 \\
Kolmogrov-Smirnov $Z$ & 0,074305556 \\
Asymp.Sig. (2-tailed) & $0,200^{\mathrm{c}, \mathrm{d}}$ \\
\hline
\end{tabular}

Sumber : Olah Data SPSS 25.02020.

Berdasarkan pada Tabel 2, dapat diketahui bahwa model regresi yang dihasilkan sudah memenuhi asumsi normalitas atau data berditribusi normal.

Hasil uji Multikolenearitas dapat dilihat pada Tabel 3.

Tabel 3. Hasil Uji Multikolenearitas

\begin{tabular}{|l|l|r|}
\hline \multirow{2}{*}{ Model } & \multicolumn{2}{|l|}{ Colenearity Statistic } \\
\cline { 2 - 3 } & Tolerance & \multicolumn{1}{|l|}{ VIF } \\
\hline 1 DPK & 0,308333333 & 2.254 \\
NPL & 0,30625 & 2.267 \\
SUKU & 0,681944444 & 1.019 \\
BUNGA & & \\
KREDIT & & \\
\hline
\end{tabular}

Sumber : Olah Data SPSS 25.0 2020.

Berdasarkan Tabel 3, dapat diketahui bahwa tidak terdapat variabel bebas yang memiliki nilai tolerance kurang dari 0.10 dan juga tidak ada variabel bebas yang memiliki nilai VIF lebih dari 10, maka dari pada itu model regresi bebas dari gejala multikolinearitas.

Hasil uji Autokorelasi dapat dilihat pada Tabel 4.

Tabel 4. Hasil Uji Autokorelasi dengan Durbin-Watson

\begin{tabular}{|l|c|}
\hline Model & Durbin-Watson \\
\hline 1 & 0,389583333 \\
\hline
\end{tabular}

Sumber : Olah Data SPSS 25.0 2020.

Berdasarkan Tabel 4 dapat diketahui bahwa nilai untuk D-W adalah sebesar 0.561. Sesuai dengan kriteria pengambilan keputusan, nilai D-W pada hasil uji penelitian ini sebesar 0.561 berada diantara -2 dan +2 yang berarti tidak ada autokorelasi.

Hasil uji Heterokedastisitas dapat dilihat pada Tabel 5.

Tabel 5. Hasil Uji Heterokedastisitas dengan Uji Glejser

\begin{tabular}{|l|r|l|}
\hline Model & \multicolumn{1}{|l|}{ t } & Sig. \\
\hline 1 (Constanta) & 0.059 & 0,6618056 \\
DPK & 1.103 & 0,1916667 \\
NPL & 1.649 & 0,0736111 \\
SUKU BUNGA & -1.141 & 0,1805556 \\
KREDIT & & \\
\hline
\end{tabular}

Dari Tabel 5 dapat diketahui bahwa masing-masing model memiliki nilai signifikansi lebih 
dari 5\%. Dengan demikian, penelitian ini bebas dari gejala heterokedastisitas.

Berdasarkan hasil uji asumsi klasik maka diketahui pada persamaan regresi tidak terjadi gejala heterokedastisitas, tidak terjadi gejala multikolenearitas tidak terjadi autokorelasi, dan distribusi data normal, sehingga model regresi bisa digunakan karena mendapatkan hasil prediksi yang baik atau bisa memberikan manfaat dengan benar.

\section{Analisis Regresi Linear Berganda}

Hasil uji regresi linear berganda dapat dilihat pada Tabel 6.

Tabel 6. Rekaptulasi Hasil Analisis Regresi Linear Berganda

\begin{tabular}{|l|r|r|}
\hline \multirow{2}{*}{ Model } & \multicolumn{2}{|c|}{ Unstandardized } \\
\cline { 2 - 3 } & \multicolumn{1}{|l|}{ B } & \multicolumn{1}{|c|}{ Std. Error } \\
\hline 1 (Constanta) & 5.171 & 1.050 \\
DPK & -0.089 & 0.026 \\
NPL & -0.108 & 0.046 \\
SUKU & 1.654 & 0,40763888 \\
BUNGA & & 9 \\
KREDIT & & \\
\hline
\end{tabular}

Sumber : Olah Data SPSS 25.02020.

Berdasarkan Tabel 6, diperoleh persamaan regresi linear berganda adalah:

$$
Y=5.171-0.089 X_{1}-0.108 X_{2}+1.654 X_{3}
$$

Memberikan informasi bahwa: a $=5.171$ artinya, jika DPK, NPL, dan suku bunga kredit nilainya 0 (nol) maka tingkat ROA pada tahun 2013-2016 nilainya positif yaitu sebesar 5.171. $\mathrm{b}_{1}$ $=-0.089$ artinya, bahwa setiap peningkatan DPK sebesar Rp. 1 maka ROA pada tahun 2013-2016 akan mengalami penurunan sebesar 0.089, dengan asumsi variabel independen NPL dan suku bunga kredit konstan atau tetap. $b_{2}=-0.108$ artinya, bahwa setiap peningkatan NPL sebesar $1 \%$ maka ROA pada tahun 2013-2016 akan mengalami penurunan 0.108, dengan asumsi variabel independen NPL dan suku bunga kredit konstan atau tetap. $b_{3}=1.654$ artinya, bahwa setiap peningkatan suku bunga kredit sebesar 1\% maka ROA pada tahun 2013-2016 akan mengalami peningkatan sebesar 1.654, dengan asumsi variabel independen NPL dan suku bunga kredit konstan atau tetap.

\section{Analisis Determinasi}

Analisis determinasi dilakukan untuk mengetahui sejauh mana variasi variabel bebas yaitu DPK $\left(\mathrm{X}_{1}\right)$, NPL $\left(\mathrm{X}_{2}\right)$, dan Suku bunga kredit $\left(\mathrm{X}_{3}\right)$ terhadap variabel ROA $(\mathrm{Y})$. Hasil uji analisis determinasi dapat dilihat pada Tabel 7.

Tabel 7. Hasil Uji Analisis Determinasi

\begin{tabular}{|l|l|l|l|}
\hline Model & R & R Square & $\begin{array}{l}\text { Adjusted } \mathrm{R} \\
\text { Square }\end{array}$ \\
\hline 1 & $0.801^{\mathrm{a}}$ & 0,445138889 & 0,428472222 \\
\hline
\end{tabular}

Sumber : Olah Data SPSS 25.0 2020. 
Berdasarkan Tabel 7, diperoleh koefisien determinasi adalah 61,7\%. Artinya sebesar $61.7 \%$ ROA pada PT. BPR Suryajaya Ubud tahun 2013-2016 dipengaruhi oleh variabel DPK $\left(\mathrm{X}_{1}\right)$, NPL $\left(\mathrm{X}_{2}\right)$, dan Suku bunga kredit $\left(\mathrm{X}_{3}\right)$, dan sisanya sebesar 38.3\% dipengaruhi oleh variabel lain yang tidak diteliti pada variabel ini.

\section{Uji Signifikansi Simultan (f-test)}

Uji $\mathrm{F}$ digunakan untuk mengetahui apakah variabel independen secara bersama-sama (simultan) berpengaruh terhadap variabel dependen. Hasil uji hipotesis menggunakan uji statistic F (f-tes) dapat dilihat pada Tabel 8.

Tabel 8. Hasil Uji Sinifikansi Simultan (f-test) pada Tabel Anova

\begin{tabular}{|ll|l|l|}
\hline Model & F & Sig. \\
\hline $\begin{array}{l}\text { 1 } \\
\text { Regression } \\
\text { Residual } \\
\text { Total }\end{array}$ & 26.209 & $0.000^{\mathrm{b}}$ \\
\hline
\end{tabular}

Sumber : Olah Data SPSS 25.0 2020.

Berdasarkan Tabel 8, hasil uji statistik F (f-test) diperoleh nilai F-hitung sebesar 23.258 dan F-tabel sebesar 2.21. Sehingga 23.258 > 2.21 atau F-hitung > F-tabel dengan signifikansi 0,000 < 0,05. Jadi, dapat disimpulkan bahwa DPK, NPL, dan suku bunga kredit secara bersama-sama (simultan) berpengaruh terhadap ROA (Ha diterima).

\section{Uji Signifikansi Parsial (t-test)}

Uji t digunakan untuk mengetahui apakah variabel independen secara sendiri-sendiri (parsial) berpengaruh terhadap variabel dependen. Hasil uji Signifikansi Parsial t (t-test) dapat dilihat pada Tabel 9.

Tabel 9. Hasil Uji Signifikansi Parsial (t-test)

\begin{tabular}{|l|r|r|}
\hline Model & \multicolumn{1}{|l|}{ T } & \multicolumn{1}{|l|}{ Sig. } \\
\hline 1 (Constanta) & 4.923 & 0.000 \\
DPK & -3.369 & 0.002 \\
NPL & -2.343 & 0.024 \\
SUKU & 2.818 & 0.007 \\
BUNGA & & \\
KREDIT & & \\
\hline
\end{tabular}

Berdasarkan Tabel 9 diperoleh: DPK dengan nilai t-hitung $-3.369<\mathrm{t}$-tabel -1.301 , dan nilai signifikan $0.05>0.002$. Jadi, dapat disimpulkan bahwa ada pengaruh yang negatif dan signifikan secara parsial antara DPK terhadap ROA (Ha diterima). NPL dengan nilai t-hitung $-2.343<\mathrm{t}$ tabel-1.301, dengan nilai signifikan $0.024<0.10$. Jadi, dapat disimpulkan bahwa ada pengaruh yang negatif dan signifikan secara parsial antara NPL terhadap ROA (Ha diterima). Suku Bunga Kredit dengan nilai t-hitung $2.818>\mathrm{t}$-tabel 1.301 , dengan nilai signifikan $0.007<0.10$. Jadi, dapat disimpulkan bahwa ada pengaruh yang positif dan signifikan secara parsial antara Suku Bunga Kredit terhadap ROA (Ha diterima).

\section{PENUTUP}

\section{Simpulan}

Berdasarkan hasil analisis data dan pembahasan, maka didapat kesimpulan hasil penelitian di PT. BPR Suryajaya Ubud tahun 2013-2016. Ada pengaruh secara simultan antara DPK, NPL, dan Suku Bunga Kredit terhadap ROA. Ada pengaruh negatif dan signifikan antara DPK terhadap ROA. Ada pengaruh negatif dan signifikan antara NPL terhadap ROA. Ada pengaruh 
positif dan signifikan antara Suku Bunga Kredit terhadap ROA.

\section{Saran}

Dalam hal ini perlu diperhatikan untuk NPL, untuk lebih ditekankan pada ekspansi serta penerimaan dana agar dapat dilakukan penyaluran dengan baik, serta usaha dalam upaya penyelesaian kredit bermasalah agar dapat menurunkan angka NPL, serta dapat menumbuhkan laba dengan memaksimalkan penggunaan aktiva produktif.

Penghimpunan dana telah dilakukan dengan baik. Namun, untuk penyalurannya belum maksimal untuk mendapatkan laba. Meningkatkan prospek terhadap nasabah baru dan lama juga perlu dilakukan, agar dapat meningkatkan jumlah nasabah serta pendapatan dan membayar biaya bunga kepada deposan.

Untuk Suku Bunga Kredit, suku bunga dapat berubah sewaktu-waktu mengikuti perekonomian pasar keuangan. Oleh sebab itu perlu dilakukan evaluasi untuk mengantisipasi inflasi sewaktu-waktu dan juga mengukur standarisasi suku bunga agar tetap dapat menghasilkan pendapatan atau laba demi kemajuan Bank.

Menjaga ROA agar tetap stabil memang tidak mudah, namun dapat dilakukan jika perusahaan mampu membentuk manajemen dengan baik dan benar serta sesuai dengan ketentuan atau SOP yang berlaku. Meminimumkan biaya-biaya operasional serta meningkatkan ekspansi.

\section{DAFTAR PUSTAKA}

Kasmir. (2014). Analisis Laporan Keuangan. Jakarta: PT. Raja Grafindo.

Moeljadi. (2006). Manajemen Keuangan. Pendekatan Kuantitatif dan Kualitatif, Edisi Pertama.Bayu Media Publishing: Malang.

Peraturan Bank Indonesia. No. 6/10/PBI/2004 tentang Sistem Penilaian Tingkat Kesehatan Bank Umum. Diakses 3 November 2019, dari (https://www.bi.go.id/id/Default.aspx).

Peraturan Bank Indonesia No. 17/11/PBI/2015 tentang Perubahan atas Peraturan Bank Indonesia No. 15/15/PBI/2013 tentang Giro Wajib Minimum Bank Umum dalam Rupiah dan Valuta Asing bagi Bank Umum Konvensional. Diakses 1 November 2019, dari (https://www.bi.go.id/id/Default.aspx).

Sawir, Agnes. (2005). Analisis Kinerja Keuangan dan Perencanaan Keuangan Perusahaan. Jakarta: Gramedia Pustaka.

Simamora, Henry. (2000). Akuntansi Basis Pengambilan Keputusan Bisnis. Jakarta: Salemba Empat.

Suryajaya Ubud, PT BPR. (2019). Sejarah PT. BPR Suryajaya Ubud. Diakses 23 Desember 2019, dari (www.banksurya.com).

Undang -Undang No. 10 Tahun 1998 tentang Perubahan atas Undang - Undang No. 7 Tahun 1992 tentang Perbankan. Diakses 3 Desember 2019, dari (http://hukum.unsrat. ac.id/uu/uu_10_98.htm). 